\title{
0 modelo de 4 estágios como vantagem competitiva no planejamento e controle da produção (PCP)
}

O objetivo deste ensaio é difundir, no meio empresarial, o modelo de quatro estágios desenvolvido por Wheelwright et al. (1985) como ferramenta processual no Planejamento e Controle da Produção. Da mesma forma, descrevemos seus estágios mediante uma elaboração contextualizada, apresentando sua relevância enquanto indicador para a gestão dentro das organizações. No desenvolvimento, há referências de artigos publicados por autores especializados em administração da produção e suas contribuições ao estudo da temática, o que enriquece e fundamenta este ensaio por meio de uma abordagem metodológica bibliográfica e descritiva. Como uma das ferramentas de gestão efetiva que auxilia a tomada de decisões enquanto mediador da avaliação para vantagem competitiva no Planejamento e Controle da Produção das empresas na condução de seus processos produtivos (bens/serviços), lançamos mão de uma reflexão crítica no intuito de auxiliar administradores da produção como também demais interessados, na compreensão do referido modelo para o Planejamento e Controle da Produção no novo contexto da 4 ㅇ Revolução Industrial.

Palavras-chave: Modelo de quatro estágios; Planejamento e Controle da Produção; Planejamento Estratégico; Objetivos de Desempenho; Vantagem Competitiva.

\section{The 4-stage model as a competitive advantage in production planning and control (PCP)}

The purpose of this essay is to disseminate, in business, the four-stage model developed by Wheelwright et al. (1985) as a procedural tool in Production Planning and Control. In the same way, we describe its stages through a contextualized elaboration, presenting its relevance as an indicator for management within organizations. In the development, there are references of articles published by authors specialized in production management and their contributions to the study of the theme, which enriches and underpins this essay through a bibliographical and descriptive methodological approach. As one of the effective management tools that assists decision making as a mediator of the assessment for competitive advantage in the Production Planning and Control of companies in conducting their production processes (goods / services), we use critical reflection to help production managers as well as other interested parties, in understanding this model for Production Planning and Control in the new context of the 4th Industrial Revolution.

Keywords: Four stage model; Planning and production control; Strategic planning; Performance Objectives; Competitive advantage.

Topic: Planejamento, Estratégia e Competitividade

Reviewed anonymously in the process of blind peer.
Received: 04/06/2019

Approved: 05/09/2019
Gean Breda Queiros (iD)

Universidade Federal do Espírito Santo, Brasi

http://lattes.cnpq.br/9520588940694258

https://orcid.org/0000-0003-0242-773X

geanbreda@hotmail.com
Referencing this:

QUEIROS, G. B.. O modelo de 4 estágios como vantagem competitiva no planejamento e controle da produção (PCP). Management Journal, v.1, n.2, p.21-28, 2019. DOI: http://doi.org/10.6008/CBPC26746417.2019.001.0002 


\section{INTRODUÇÃO}

O Planejamento e Controle da Produção (PCP) está relacionado com toda a atividade dentro do meio empresarial. A competitividade e globalização entre as empresas estimularam as mesmas, a cada vez mais, estarem focando na melhoria contínua de seus processos entre produtos e serviços, com alguns tipos de estratégias. Assim, o PCP, juntamente com atividades estudadas minuciosamente, ajuda no crescimento e melhoria entre as concorrentes nacionais e multinacionais.

O propósito fundamental do PCP consiste na utilização e no gerenciamento das atividades de produção, gerenciamento da parte operacional e o planejamento da ação: o mesmo faz o trabalho de estipular o que será produzido, quando será produzido e qual o momento certo de estar colocando em prática essa atividade. A empresa que não planeja ou não controla a produção, tem uma enorme chance de adquirir algumas dificuldades que irão surgir, tanto na produção quanto na qualidade, proporcionando assim, uma eventual perca de ativos.

A administração da produção é a responsável pelo gerenciamento do processo produtivo. Desta forma, os gerentes precisam procurar alternativas para estarem implantando dentro da empresa, um modo de estar protegida. Uma delas é a proposição da utilização do Modelo de quatro estágios, de Wheelwright et al. (1985), onde basicamente se indica a parar de cometer erros no processo produtivo e assim atingir padrões mínimos aceitáveis; a realização de benchmarking para obter resultados tão bons quanto os da concorrência; a busca pela melhoria contínua, assim conseguindo superar o adversário no mercado e a inovação e criação de produtos e serviços continuamente.

Nossas reflexões neste ensaio caracterizam o papel do modelo de quatro estágios inserido no Planejamento e Controle da Produção de uma organização, seja ela operante na área de produtos e/ou serviços, como também apresentam seus benefícios para o planejamento estratégico quando na elaboração de sistemas e métodos inovadores em atividades empreendedoras.

Nessa direção, temos em Chiavenato (1997) uma afirmação-guia quando destaca que o controle é a função administrativa que consiste em medir e corrigir o desempenho para assegurar que os planos sejam executados da melhor maneira possível. Assim, temos como objetivo analisar para o contexto empresarial, a importância do modelo de quatro estágios frente o Planejamento e Controle da Produção. Da mesma forma, buscamos descrever seus estágios mediante uma elaboração contextualizada que apresente sua relevância enquanto indicador/ferramenta para a gestão dentro das organizações.

Nas reflexões, buscamos referências em artigos publicados por outros autores que enriquecem e fundamenta nosso estudo tornando nossa abordagem metodológica bibliográfica e descritiva. Propomos, com esse artigo, ter em mãos um produto informativo que vá auxiliar administradores da produção como também demais interessados, na compreensão do modelo de quatro estágios para o Planejamento e Controle da Produção no novo contexto da 40 Revolução Industrial.

Sempre se ouve falar que as empresas estão em concorrência constante. E na verdade, estão. Ainda mais no Brasil atual em referência ao ano de 2019, um momento ímpar na história onde a crise financeira 
assola a liberação de recursos públicos prejudicando atividades fins por questões políticas e a economia não encontrando o seu equilíbrio segue sentido contrário em consequência desta. As empresas em si, embora tenham seus programas específicos de gestão, sendo elas encaixadas em todas as categorias desde as micros até as grandes, ainda arrastam um problema de cunho gerencial em sua totalidade: sempre haverá falhas em seu processo produtivo, seja ele humano, de maquinários, de layouts (espaços), etc..

Dentre essas empresas, muitas ainda permanecem míopes, ou seja, não enxergam as oportunidades muito menos as ameaças que as rondam. Principalmente em seu processo produtivo (produtos/serviços) as empresas devem visualizar o cenário ao qual estão inseridos os seus recursos para que a transformação do bem ou serviço ocorra de forma significativa: efetiva e econômica. Aqui se faz importante a análise do papel do modelo de quatro estágios como mapa conceitual para que as empresas, num primeiro momento, tomem uma direção em seus planos estratégicos de negócios. Apresentamos nas próximas seções, a metodologia, a descrição dos conceitos ligados ao Planejamento Estratégico, os Objetivos de Desempenho e o Modelo de quatro estágios.

\section{METODOLOGIA}

Mediante a intensão do estudo, a abordagem metodológica segue os passos da pesquisa bibliográfica com a devida apresentação das informações levantadas inseridas na temática. Como produto de um estudo descritivo e reflexivo, lançamos mão do presente como ferramenta de ganho em vantagem competitiva para as organizações que elaboram seus PCPs.

\section{DISCUSSÃO TEÓRICA}

\section{Planejamento Estratégico}

Segundo Silva (2001, citado por RODRIGUES, 2005) o planejamento estratégico é a parte fundamental da administração, e tem suas origens nas mais remotas civilizações, desde o momento em que o homem precisou realizar tarefas e organizar recursos disponíveis. A afirmação de Chiavenato (1987, citado por PAIVA et al., 2010) colabora com o excerto na medida em que o planejamento estratégico se refere à maneira pela qual uma empresa pretende aplicar uma determinada estratégia para alcançar os objetivos propostos. É geralmente um planejamento realizável em longo prazo.

Para Kotler (1992, citado por RODRIGUES, 2005) o planejamento estratégico é definido como o processo gerencial de desenvolver e manter uma adequação razoável entre os objetivos de desempenho, os recursos da empresa e as mudanças e oportunidades de mercado. O objetivo é orientar e reorientar os negócios e produtos da empresa de modo que gere lucros e crescimento satisfatórios.

Aliás, é interessante a abordagem de Oliveira (2002, citado por MONTEIRO et al., 2012) que define como objetivo do planejamento estratégico proporcionar sustentação metodológica para se estabelecer a melhor direção a ser seguida pela empresa, visando aperfeiçoar o grau de interação interna e externamente com o ambiente e consequentemente com os diretamente envolvidos (stakeholders), atuando, assim, de 
forma inovadora, estratégica e tecnologicamente superior. Envolve não somente a formulação de objetivos como também metas a serem seguidas para se alcançar tais objetivos.

Assim, observa-se que o planejamento estratégico examina as questões principais da organização, pois se trata de um processo de planejamento formalizado como, por exemplo, a análise SWOT $^{1}$ e de longo alcance para a definição das metas e dos objetivos organizacionais considerado a análise do ambiente externo e interno. Em outra conceituação, Drucker (1975, citado por PORTO, 2006) define planejamento estratégico como um processo contínuo de tomadas de decisões organizacionais, no momento presente, de forma a se ter, da melhor maneira, o conhecimento do futuro, bem como o empenho, no sentido de se cumprir tais decisões.

Mintzberg (1987, citado por TERENCE, 2002) alega que as organizações, se pretendem gerenciar o futuro, devem compreender o passado, pois através do conhecimento dos padrões anteriores, é que serão capazes de conhecer suas capacidades e seus potenciais. Portanto, o processo de planejamento estratégico envolve uma análise do passado, do presente e um vislumbramento do futuro da organização.

Nessa direção, as colocações de Tiffany et al. (1988, citado por TERENCE, 2002) vem corroborar com Mintzberg, pois o planejamento estratégico não é uma ciência que mostra o certo e o errado em relação ao futuro, e sim, uma ferramenta que fornece à organização uma visão do futuro, aumentando a probabilidade da empresa aproveitar as oportunidades e explorar suas potencialidades. Segundo Terence (2002), o planejamento estratégico é uma visão específica do futuro, através da qual a empresa analisa o setor de atuação, o mercado, os concorrentes, os produtos e serviços, os valores a serem oferecidos ao cliente, as vantagens a curto e longo prazo, a lucratividade, entre outros aspectos.

Em face ao exposto, se observa que o planejamento estratégico procura ordenar as ideias das pessoas de todas as áreas da produção em busca de maximizar os resultados das operações e minimizar os riscos nas tomadas de decisões, de forma que se possa ter uma visão clara do caminho que se deve seguir. Assim, em um mercado atual tão competitivo em pleno século XXI, a elaboração de um plano estratégico já se configura como atividade-raiz em sua organicidade sendo básica e obrigatória ao mesmo tempo para que as organizações e os administradores possam ter condições de dar orientação aos objetivos de desempenho da empresa.

\section{Objetivos de desempenho}

Os objetivos de desempenho podem ser citados também como prioridades competitivas que impactam nos processos produtivos de uma organização. Eles são especificamente as características pela qual o consumidor optou em comprar/adquirir o seu produto/serviço. Os mais mencionados no mundo corporativo e de maior importância são: Custo, Qualidade, Confiabilidade, Flexibilidade e Rapidez. Estes são citados pela maioria dos autores que discorrem sobre esta literatura. Alguns expoentes são Hill (2002), Correa (2004), Slack et al. (2008, citado por PASQUALINI et al., 2010).

\footnotetext{
1 Para compreensão da análise SWOT ver informações da Endeavor (organização que estuda e pesquisa temas ligados à área de negócios/empreendedorismo).
} 
Esses objetivos por sua vez são então alocados de acordo com sua importância. A maneira muitas vezes utilizada é o método apresentado por Hill (2002, citado por PASQUALINI et al., 2010), classificando os objetivos de desempenho em Ganhadores de Pedido, Qualificadores e Menos Importantes. Slack et al. (2009) são um dos idealizadores deste estudo, tanto que propuseram uma "matriz importância x desempenho".

Correa (1993, citado por COSTA, 1999) também explica a definição do que seria esta classificação, o que são cada uma delas. Os critérios Qualificadores são os critérios que o consumidor irá definir que te enquadrará a empresa em um nível de vantagens oferecida, algumas destas vantagens dos quais ele não abriria mão, ou seja, para aquele consumidor, para a empresa atendê-lo é preciso pelo menos que a empresa ofereça algumas vantagens.

Os critérios Ganhadores de Pedidos são as qualidades que o cliente opte por escolher a sua empresa dentre as demais que ele julgou qualificadas a atendê-lo. Os critérios Menos Importantes são as demais vantagens oferecidas pela empresa que não irá afetar a preferência de seu cliente. Observa-se que a empresa precisa realizar um estudo de quem é o consumidor da empresa, levantando dados em pesquisas para se descobrir o que estes consumidores esperam da minha organização.

Slack et al. (2009) tende a ligar os objetivos de desempenho às vantagens competitivas da empresa. Eles nos apresentam os cinco objetivos de desempenho citados acima que são ligados a decisões que diretores e gerentes se submetem para contribuir com a competitividade da empresa, sendo que esta é adotada por Slack et al. (2009) com o nome de "vantagem baseada em produção". Slack et al. (2009) utiliza perguntas relacionadas a cada objetivo, como ferramenta para adquirir estas vantagens competitivas. Observe a figura 1, que retrata a posição de Slack et al. (2009).

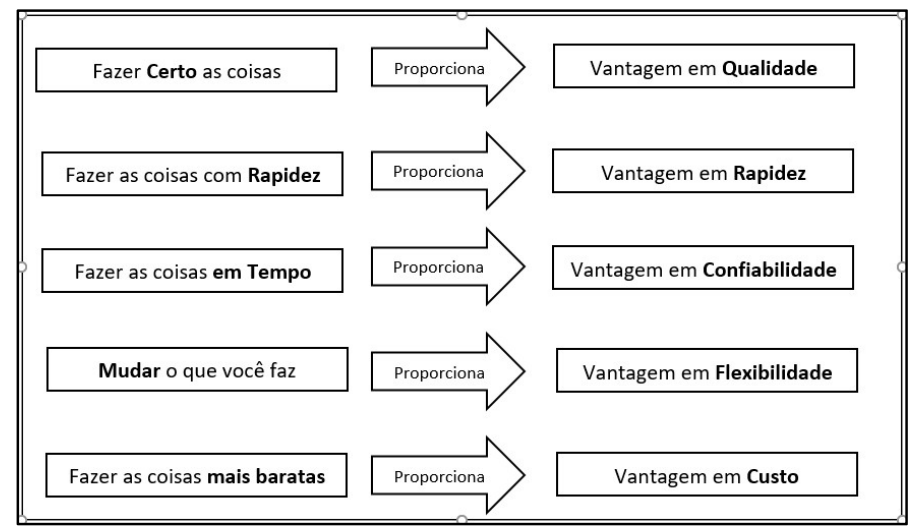

Figura 1: Vantagem baseada em produção. Fonte: Slack et al. (2009).

\section{Modelo de quatro estágios}

A função produção pode assumir diversos papéis em uma empresa, e estes podem ser caracterizados a partir de um continuum que identifica quatro estágios das organizações frente a esta questão (WHEELWRIGHT et al., 1985, citado por COSTA, 1999). Elaborado pelos professores Wheelwright e Hayes da Harvard, com contribuição do professor Chase da Califórnia, o modelo pode ser usado para avaliar o papel competitivo e a contribuição da função produção de qualquer tipo de empresa (SLACK et al., 2009). Segundo 
os autores, o modelo traça a progressão dessa função, desde o papel largamente negativo do Estágio 1 de produção, para se tornar o elemento central de estratégia competitiva no excelente Estágio 4 de produção.

Desta forma, a visibilidade que o modelo apresenta norteia os gestores da produção como também todos os envolvidos no processo produtivo a compreenderem em qual posição a empresa se situa no momento e aonde querem chegar. Por outro lado, o modelo em si, é uma ferramenta de gestão efetiva voltada para a estratégia empresarial, pois identifica cada estágio da cadeia produtiva e contribui para a tomada de decisão. Nesse sentido, Slack et al. (2009) apresenta o modelo criado pelos professores Hayes e Wheelwright, identificando cada estágio conforme apresentado.

Estágio 1: Neutralidade Interna. No primeiro estágio a produção é considera neutra ou incapaz de influenciar a competitividade. São estabelecidos esforços para minimizar os efeitos negativos deste 'Mal necessário'. Em síntese, no estágio 1: Nível mais fraco de contribuição da função produção; A produção é considerada um 'mal necessário'; A função produção está apenas aspirando atingir os padrões mínimos aceitáveis demandados pelo restante da organização; e 'Internamente neutra', posição esta que não procura atingir algo positivo, mas pelo menos evita erros maiores.

Estágio 2: Neutralidade Externa. Neste estágio, passa-se a buscar uma paridade com os principais competidores, onde: A ideia sobre a primeira etapa de rompimento do Estágio 1 é a função produção começar comparando-se com empresas ou organizações similares. Isso pode não a levar imediatamente à "primeira divisão" de empresas do mercado, mas, pelo menos, pode levá-la a aspirar a atingir essa posição e a comparar-se em relação ao desempenho das concorrentes. Certamente, a função produção não estará prejudicando a empresa. Ela pode não ser muito criativa na forma de administrar suas operações, mas estará tentando ser 'apropriada' adotando a 'melhor prática' de suas concorrentes. Seguindo as melhores ideias e normas de desempenho das demais empresas do setor, tentará ser "externamente neutra".

Estágio 3: Apoio interno. No estágio 3, a produção é utilizada para sustentar uma força na posição competitiva da empresa. A produção oportuniza sustentação interna para a estratégia de negócio. Em resumo: Atinge a 'primeira divisão' em seu mercado; está junto às melhores empresas; A produção aspira ser, clara e certamente, a melhor do mercado; obtém visão clara da concorrência ou dos objetivos estratégicos da empresa; organiza e desenvolve recursos de produção para superar as deficiências; e Assume papel de 'implementadora' da estratégia.

Estágio 4: Apoio externo. No quarto e último estágio, a produção passa a assumir o papel de sustentação externa, as empresas fazem esforços para inovar e antecipar melhores práticas de produção e novas tecnologias, ou seja, a estratégia competitiva decorre em grande parte da capacidade produtiva da empresa. Podemos destacar que: Função produção como provedora da base para seu sucesso competitivo futuro; A produção olha para o longo prazo; Prevê prováveis mudanças nos mercados e na oferta de suprimentos; Desenvolve estratégias que proporcionam à empresa o desempenho que será exigido para competir no mercado futuro; e a função produção é criativa e proativa (organiza recursos inovando-os e se adapta a mudanças dos mercados). Configurando uma melhor visualização, a figura 2 retrata o modelo de quatro estágios para compreensão. 


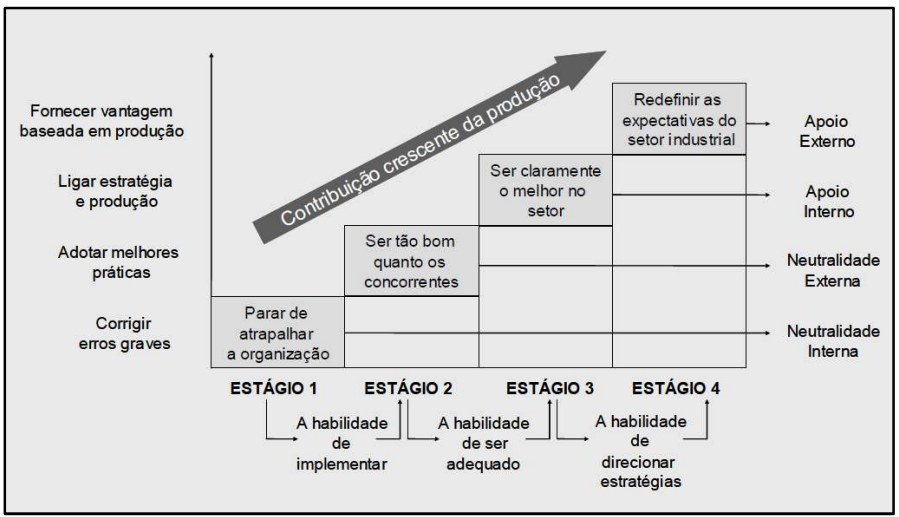

Figura 2: Modelo de quatro estágios. Fonte: Slack et al. (2009).

Do mesmo modo, a fim de elucidar a análise do modelo, os professores Hayes e Wheelwright (SLACK et al., 2009), apresentam o mesmo. Ele avalia o desempenho da produção pelas aspirações da função. Em outras palavras, procura saber como a função produção gostaria de ser vista e como as demais funções da empresa realmente a veem. Nessa direção, à medida que as empresas se movimentam do Estágio 1 ao Estágio 4, há uma mudança progressiva. De início, a contribuição da produção é negativa e envolve apenas aspectos operacionais. No decorrer dos estágios, a contribuição passa a ser positiva, chegando à estratégica na fase final. A empresa passa a confiar na vantagem 'baseada em produção' para definir sua estratégia competitiva.

\section{CONSIDERAÇÕES FINAIS}

Com base nessa apresentação, podemos observar que a importância do modelo de quatro estágios para o Planejamento e Controle da Produção, vai muito além do que podemos observar na prática: ele influencia desde o princípio do pensamento de produção, quando da elaboração do plano estratégico de negócios, até a própria prática e sua eficiência total, tornando-se uma ferramenta de gestão efetiva.

É importante ressaltar que o modelo de quatro estágios deve ser utilizado como ferramenta diferencial no mercado, como apoio que vá impulsionar a boa gestão de uma empresa e colocá-la um passo à frente de seus concorrentes, visando observar de forma sistêmica, o todo de dentro para fora da organização e vice-versa.

Empresas e gestores que utilizam o modelo de quatro estágios como orientador de suas decisões ganham em vantagem competitiva sobre a concorrência. Em se tratando de produção em todos os seus níveis, especialmente na função produção, o modelo de quatro estágios se torna o caminho para diferenciação no mercado capitalista, que busca sempre maximizar o lucro sobre o capital investido.

\section{REFERÊNCIAS}

CHIAVENATO, I.. Teoria Geral da Administração. São Paulo: McGraw-Hill, 1997.

COSTA, A. A. V.. O papel da função produção nas definições estratégicas adotadas pelas empresas. Rio de Janeiro: ABEPRO, 1999.
MONTEIRO, V. G.; SOARES, F. C.. Planejamento estratégico como ferramenta competitiva para empresas da região central de poços de caldas. Gestão e Conhecimento, p.181197, 2012.

PAIVA, L. M.; LEPRE, M. A.; PINHEIRO, W.. A importância do planejamento estratégico. Governador Valadares: UNIVALE, 2010. 
PAQUALINI, F.; LOPES, A. O.; SIEDENBERG, D.. Gestão da Produção. ljuí: EDUNIJUÍ, 2010.

PORTO, M. A. G.. O Planejamento estratégico como forma de otimizar o gerenciamento nas organizações. In: SIMPÓSIO DE ENGENHARIA DE PRODUÇÃO, 13. Anais. Bauru: 2006.

RODRIGUES, P.. O Planejamento Estratégico dentro do Conceito de Administração Estratégica. Curitiba: 2005.

SLACK, N.; CHAMBERS, S.; JOHNSTON, R.. Administração de Produção. 3 ed. São Paulo: Atlas, 2009.
TERENCE, A. C. F.. Planejamento estratégico como ferramenta de competitividade na pequena empresa: desenvolvimento e avaliação de um roteiro prático para o processo de elaboração do planejamento. Dissertação (Mestrado em Engenharia de Produção) - Universidade de São Paulo, São Carlos, 2002. DOI: http://doi.org/10.11606/D.182002.tde-27052004-110812

WHEELWRIGHT, S. C.; HAYES, R. H.. Competing Through Manufacturing. Cambridge: Harvard Business Review, 1985.

A CBPC - Companhia Brasileira de Produção Científica (CNPJ: 11.221.422/0001-03) detém os direitos materiais desta publicação. Os direitos referem-se à publicação do trabalho em qualquer parte do mundo, incluindo os direitos às renovações, expansões e disseminações da contribuição, bem como outros direitos subsidiários. Todos os trabalhos publicados eletronicamente poderão posteriormente ser publicados em coletâneas impressas sob coordenação da Sapientiae Publishing, da Companhia Brasileira de Produção Científica e seus parceiros autorizados. Os (as) autores (as) preservam os direitos autorais, mas não têm permissão para a publicação da contribuição em outro meio, impresso ou digital, em português ou em tradução. 